\title{
CLINICAL FEATURES AND OUTCOMES OF H1N1 PNEUMONIA IN A TERTIARY CARE HOSPITAL
}

Dhanasekar T1, Kalaiselvan'2, Yeldho Eason Verghese3, Renuka M. K4, Arunkumar A. $S^{5}$

${ }_{1}^{1}$ Associate Professor, Department of Pulmonary Medicine, Sri Ramachandra Medical College and Research Institute, Sri Ramachandra University.

${ }^{2}$ Assistant Professor, Department of Critical Care Medicine, Sri Ramachandra Medical College and Research Institute, Sri Ramachandra University.

${ }_{3}^{3}$ Post Graduate, Department of Critical Care Medicine, Sri Ramachandra Medical College and Research Institute, Sri Ramachandra

University.

${ }^{4}$ Associate Professor, Department of Critical Care Medicine, Sri Ramachandra Medical College and Research Institute,

Sri Ramachandra University.

${ }^{5}$ Professor and HOD, Department of Critical Care Medicine, Sri Ramachandra Medical College and Research Institute, Sri Ramachandra University.

\section{ABSTRACT}

Influenza virus causes mild-to-severe acute respiratory illness. H1N1 bronchopneumonia carries a higher mortality.

\section{MATERIALS AND METHODS}

Study was a prospective observational study conducted in a 24 bedded multidisciplinary ICU from January 2010 to December 2010. We included all adult patients admitted to our intensive care unit presenting with clinical features/suspicion of H1N1 bronchopneumonia and respiratory failure. These patients also subsequently tested positive for H1N1 Reverse-Transcriptase Polymerase Chain Reaction (RT-PCR) assay. Data was collected on demography, co-morbid illness, APACHE II and SOFA scores, organ failure and support. Outcome data on mortality, ICU LOS and ventilator days was also collected.

\section{RESULTS}

28 patients with $\mathrm{H} 1 \mathrm{~N} 1$ bronchopneumonia required intensive care treatment. Majority of patients were females $60.7 \%$ (n=17); of these 17 patients 7 patients were pregnant. Mean age of our patients was $50.6( \pm 19.1)$ years. Most common co-existing illnesses were diabetes mellitus (32.1\%) and hypertension (32.1\%) followed by bronchial asthma (10.7\%); 85.7\% patients had at least one organ dysfunction on admission, of which respiratory system was involved in $96.5 \%$ followed by renal system $57.1 \%$. Patients were sick on admission as indicated by high APACHE II (17.75 \pm 6.5$)$ and SOFA $(5.25 \pm 1.8)$ scores. Mean PaO2/FiO2 on admission was $148.9 \pm 77.2$. Severe ARDS (PaO2/FiO2 <100) was seen in $39.35 \%$ of patients. Of the 28 patients, 27 patients required ventilator support; 17 patients died out of 28 patients (mortality rate 60.7\%). Higher APACHE II, SOFA scores and low Pa02/FiO2 on admission were identified as significant risk factors for mortality.

\section{CONCLUSION}

Critically ill H1N1 pneumonia patients present with multisystem involvement and they had a high mortality in our study.

\section{KEYWORDS}

H1N1 - Pneumonia, Ventilator Associated Pneumonia, PaO2/FiO2 Ratio.

HOW TO CITE THIS ARTICLE: Dhanasekar T, Kalaiselvan, Verghese YE, et al. Clinical features and outcomes of H1N1 pneumonia in a tertiary care hospital. J. Evolution Med. Dent. Sci. 2016;5(40):2481-2484, DOI: 10.14260/jemds/2016/578

\section{INTRODUCTION}

H1N1 influenza virus causes acute respiratory illness that can range from mild flu like symptoms to severe life-threatening severe ARDS and death. WHO declared pandemic spread of H1N1 worldwide in 2009 and it is one of the leading causes of severe acute respiratory distress syndrome, especially in young patients causing significant mortality and morbidity.1,2 H1N1 bronchopneumonia carries a higher mortality (41\%), which is similar to the mortality of acute respiratory distress syndrome caused by other virus. ${ }^{3}$ Risk factors for H1N1 influenza infections includes chronic lung disease, neurological disorders, diabetes and pregnancy. ${ }^{3-5}$

Financial or Other, Competing Interest: None.

Submission 15-04-2016, Peer Review 03-05-2016,

Acceptance 06-05-2016, Published 19-05-2016.

Corresponding Author:

Dr. Dhanasekar T,

AJ 147, No. 3,

Golden Astar Apartments,

$9^{\text {th }}$ Main Road,

Anna Nagar,

Chennai - 600040 .

E-mail:drdhansekar@yahoo.com

DOI: $10.14260 /$ jemds/2016/578
H1N1 influenza virus causes severe respiratory failure; other than respiratory system involvement it can also affect other organ systems. Changes in the immune, cardiac and respiratory systems are likely mechanisms that makes young and pregnant patients more vulnerable to this disease..$^{3-6}$ Approximately, one-quarter to one-half of patients with H1N1 virus infection who were hospitalized or died had no reported coexisting medical conditions. Pregnant women (Especially those in the second or third trimester), women who are less than 2 weeks post-partum and patients with immunosuppression are at risk of severe H1N1 virus infection. Although pregnant women represent only 1 to $2 \%$ of the population, among patients with $\mathrm{H} 1 \mathrm{~N} 1$ virus infection they have accounted for up to 7 to $10 \%$ of hospitalized patients, 6 to $9 \%$ of ICU patients and 6 to $10 \%$ of patients who died.

Among patients with severe or fatal cases of H1N1 virus infection, severe obesity or morbid obesity (Body-mass index, $\geq 40$ ) has been reported at rates that are higher by a factor of 5 to 15 than the rate in the general population. In addition to obesity-associated risks, such as cardiovascular disease and diabetes, possible adverse immunologic effects and 
management problems related to obesity may be contributory.

H1N1 virus causes a broad spectrum of clinical syndromes, ranging from afebrile upper respiratory illness to fulminant viral pneumonia. Mild illness without fever has been reported in 8 to 32\% of infected persons. Most patients presenting for care have typical influenza-like illness with fever and cough, symptoms that are sometimes accompanied by sore throat and rhinorrhoea. Systemic symptoms are frequent. Gastrointestinal symptoms (Including nausea, vomiting and diarrhoea) occur more commonly in adults. Dyspnoea, tachypnoea in children, chest pain, haemoptysis or purulent sputum, prolonged or recurrent fever, altered mental status, manifestations of dehydration, and reappearance of lower respiratory tract symptoms after improvement are signs of progression to more severe disease or complications.

The principal clinical syndrome leading to hospitalization and intensive care is diffuse viral pneumonitis associated with severe hypoxaemia, ARDS and sometimes shock and renal failure. This syndrome has accounted for approximately 49 to $72 \%$ of ICU admissions for H1N1 virus infection. Rapid progression is common, typically starting on day 4 to 5 after the onset of illness and intubation is often necessary within 24 hours after admission.

Very limited Indian studies.7-8 are available regarding H1N1 viral infection in India. The current understanding and guidelines about this disease come mostly from the western literature. More Indian studies are required for better understanding of the natural process of disease in the Indian subcontinent. We planned to study the clinical profile and the outcomes of critically ill patients with H1N1 viral infection admitted to our intensive care unit.

\section{MATERIALS AND METHODS}

Study was a prospective observational study conducted in a 24 bedded multidisciplinary ICU from January 2010 to December 2010. A suspected case was defined as an influenza-like illness (temperature $\geq 37.5^{\circ} \mathrm{C}$ and at least one of the following symptoms: sore throat, cough, rhinorrhoea or nasal congestion). PCR for H1N1 was sent for all suspected cases. Patients who do not require intensive monitoring and treatment were cared in isolation wards, patients who required intensive care treatment were shifted to ICU. We included all adult patients admitted to our intensive care unit presenting with clinical features/suspicion of H1N1 bronchopneumonia and respiratory failure. These patients also subsequently tested positive for H1N1 ReverseTranscriptase Polymerase Chain Reaction (RT-PCR) assay. Patients were admitted directly from the emergency room to the Intensive Care Unit based on the judgment of the attending physician or later on upon deterioration in the wards.

Patients were started on oseltamivir and empiric antibacterial cover. Decision to initiate mechanical ventilation and other organ support is based on the decision of ICU physician. Data captured include demographic variables like age and sex, co-morbid conditions, smoking history, pregnancy, prior treatment details, lead time of admission to hospital and ICU, method of diagnosis of H1N1, outcome viz. survivor or non-survivor modes of mechanical ventilation and other ventilator settings used oxygenation parameters, use of concomitant medications like antibiotics, steroids or vasopressors, mode of nutritional support, presence of other organ failure, dialysis requirements and complications like tube displacements, barotrauma, sepsis and cardiac arrest.

\section{STATISTICAL ANALYSIS}

Frequency analysis is expressed as Mean \pm SD for continuous variables and number and percentage for categorical variables. Survivor and non-survivor characteristics were compared using Mann-Whitney test for non-parametric variables. A two tailed probability of $\mathrm{P}<0.05$ was considered significant. Univariate and multivariate analysis was done to identify the risk factors for mortality.

\section{RESULTS}

127 patients tested positive for H1N1 during the study period. Of these 127 patients 28 required intensive care treatment, clinical features and outcomes of these 28 patients were analysed. Majority of patients were females $60.7 \%$ $(n=17)$, of these 17 patients 7 patients were pregnant. Mean age of our patients was $50.6( \pm 19.1)$ years (Table 1$)$, most common co-existing illness were diabetes mellitus (32.1\%) and hypertension $(32.1 \%)$ followed by bronchial asthma (10.7\%) (Fig. 1); $85.7 \%$ patients had at least one organ dysfunction on admission of which respiratory system was involved in $96.5 \%$ followed by renal system $57.1 \%$. Patients were sick on admission as indicated by high APACHE II (17.75 \pm 6.5$)$ and SOFA (5.25 \pm 1.8$)$ scores (Table 1).

Mean $\mathrm{PaO} 2 / \mathrm{FiO} 2$ on admission was $148.9 \pm 77.2$ (Table 1). Severe ARDS (PaO2/FiO2 <100) was seen in $39.35 \%$ of patients (Fig. 2). Of the 28 patients, 27 patients required ventilator support, 23 patients were on invasive ventilation and 4 patients were on non-invasive ventilation (Table 3); 17 patients died out of 28 patients (mortality rate 60.7\%). Higher APACHE II (Fig. 3), SOFA (Fig. 4) scores and low $\mathrm{PaO} 2 / \mathrm{FiO} 2$ on admission were identified as significant risk factors for mortality (Table 2); $25 \%$ (n-7) of our patients were in the peripartum period and their mortality was $100 \%$ and all these patients had severe ARDS mean PaO2/FIO2 ratio $(70.15 \pm 15.82)$ on admission. SOFA scores were progressively worse among the non-survivors (Fig. 4); this indicates mortality in our patients was primarily due to multiorgan failure.

\begin{tabular}{|c|c|}
\hline & MEAN \pm SD \\
\hline AGE (years) & $50.6 \pm 19.1$ \\
\hline HR (/min) & $112 \pm 18.2$ \\
\hline MAP (mmHg) & $88.7 \pm 12.5$ \\
\hline RR (/min) & $29.5 \pm 6.6$ \\
\hline PCO2 (mmHg) & $35.9 \pm 13.5$ \\
\hline $\mathrm{PO}_{2} / \mathrm{FiO2}$ & $148.9 \pm 77.2$ \\
\hline GCS & $13 \pm 3.5$ \\
\hline Total Count (/cu mm) & $10572 \pm 5125$ \\
\hline PLATELETS (/cu mm) & $1.9 \pm 1.1$ \\
\hline S. CREATININE (mg/dL) & $1.3 \pm 0.9$ \\
\hline T. BILIRUBIN (mg/dL) & $1.2 \pm 1.1$ \\
\hline APACHE II & $17.75 \pm 6.5$ \\
\hline SOFA & $5.25 \pm 1.8$ \\
\hline Organ Failure (\%) & $96.5 \%$ \\
\hline Respiratory & $57.1 \%$ \\
\hline Renal & $39.2 \%$ \\
\hline CNS & $28.6 \%$ \\
\hline Coagulation & $14.3 \%$ \\
\hline Hepatic & $7.1 \%$ \\
\hline Cardiovascular & \\
\hline Table 1: Patient Characteristics \\
\hline
\end{tabular}




\begin{tabular}{|c|c|c|c|}
\hline & $\begin{array}{c}\text { Survivors } \\
(n=11) \\
\text { MEAN } \pm \text { S.D }\end{array}$ & $\begin{array}{c}\text { Non-Survivors } \\
(n=17) \text { MEAN } \pm \text { S.D }\end{array}$ & $\begin{array}{c}P \text { - } \\
\text { value }\end{array}$ \\
\hline AGE (years) & $62.1 \pm 10.8$ & $42.9 \pm 19.7$ & $<0.05$ \\
\hline $\operatorname{HR}(/ \min )$ & $103.2 \pm 14.1$ & $118.5 \pm 18.5$ & 0.05 \\
\hline MAP (mmHg) & $86.9 \pm 14.3$ & $89.9 \pm 11.4$ & 0.54 \\
\hline RR (min) & $26.0 \pm 3.4$ & $31.6 \pm 7.3$ & 0.06 \\
\hline PCO2 (mmHg) & $35.7 \pm 10.8$ & $36.1 \pm 14.2$ & 0.42 \\
\hline P02/FiO2 & $207.5 \pm 40$ & $110.9 \pm 71.9$ & $<0.05$ \\
\hline GCS & $14.2 \pm 1.5$ & $12.2 \pm 4.2$ & 0.14 \\
\hline $\begin{array}{l}\text { Total Count (cu } \\
\mathrm{mm})\end{array}$ & $12083 \pm 4880$ & $9594 \pm 5187$ & 0.21 \\
\hline $\begin{array}{l}\text { Platelets (cu } \\
\mathrm{mm} \text { ) }\end{array}$ & $2.15 \pm 1.1$ & $1.8 \pm 1.4$ & 0.30 \\
\hline $\begin{array}{l}\text { S. Creatinine } \\
(\mathrm{mg} / \mathrm{dL})\end{array}$ & $1.3 \pm 1.1$ & $1.2 \pm .9$ & 0.45 \\
\hline $\begin{array}{l}\text { T. Bilirubin } \\
\text { (mg/dL) }\end{array}$ & $0.9 \pm .8$ & $2.1 \pm 1.8$ & 0.26 \\
\hline \multicolumn{4}{|l|}{ Outcome data } \\
\hline ICU LOS & $8.8 \pm 7.6$ & $7.7 \pm 3.6$ & 0.60 \\
\hline Ventilator days & $5.6 \pm 7.1$ & $7.3 \pm 4$ & 0.42 \\
\hline $\begin{array}{l}\text { Ventilator free } \\
\text { days }\end{array}$ & $3.7 \pm 1.4$ & $0.4 \pm 1.2$ & $<0.05$ \\
\hline $\begin{array}{l}\text { Mean Tidal } \\
\text { Volume }(\mathrm{mL})\end{array}$ & $411 \pm 20.4$ & $387 \pm 27.2$ & 0.19 \\
\hline $\begin{array}{l}\text { Maximum PEEP } \\
(\mathrm{cm} 2 \mathrm{H} 20)\end{array}$ & $9 \pm 2.5$ & $15.4 \pm 3.6$ & $<0.05$ \\
\hline $\begin{array}{l}\text { Positive fluid } \\
\text { balance (mL) }\end{array}$ & $558 \pm 423$ & $1062 \pm 452$ & $<0.05$ \\
\hline Worst $\mathrm{PO}_{2} / \mathrm{FIO} 2$ & $178.8 \pm 41.7$ & $73.5 \pm 42.5$ & $<0.05$ \\
\hline
\end{tabular}

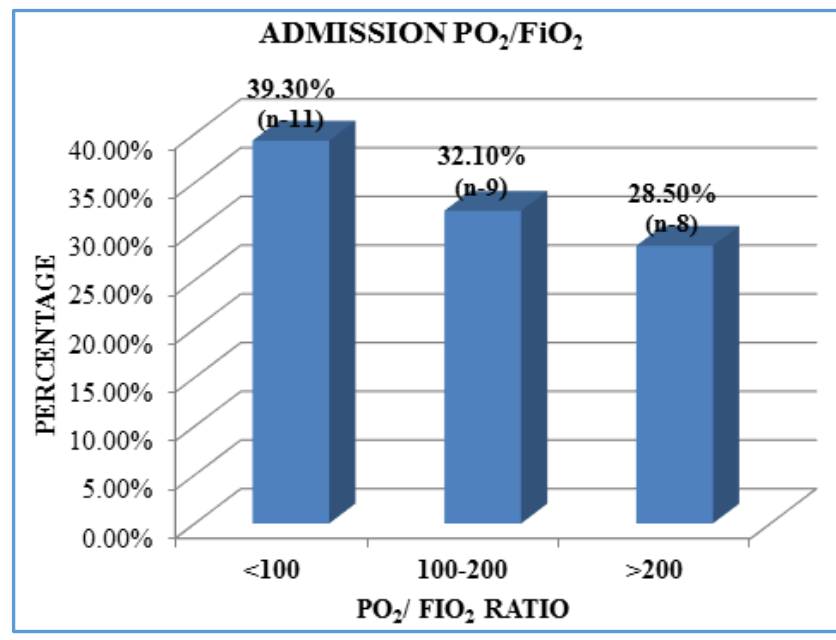

Fig. 2: Admission Pa02/FiO2 Ratio of Patients with H1N1 Bronchopneumonia

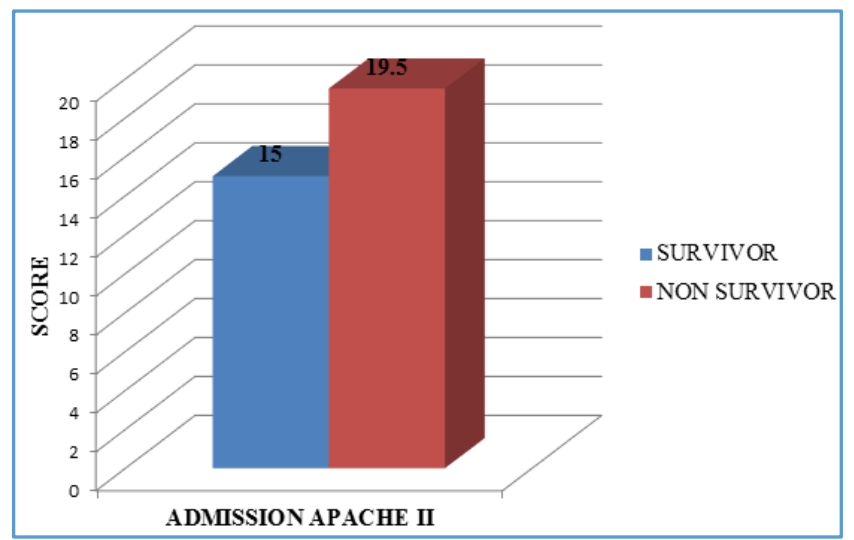

\begin{tabular}{|c|c|c|}
\hline & n & Percentage \\
\hline Any form of Ventilation & 27 & $96.4 \%$ \\
\hline Invasive Ventilation & 23 & $82.1 \%$ \\
\hline NIV & 11 & $39.3 \%$ \\
\hline Failed NIV & 7 & $25 \%$ \\
\hline NIV ONLY & 4 & $14.3 \%$ \\
\hline NONE & 1 & $3.6 \%$ \\
\hline Table 3: Ventilatory Characteristics of Patients \\
\hline
\end{tabular}

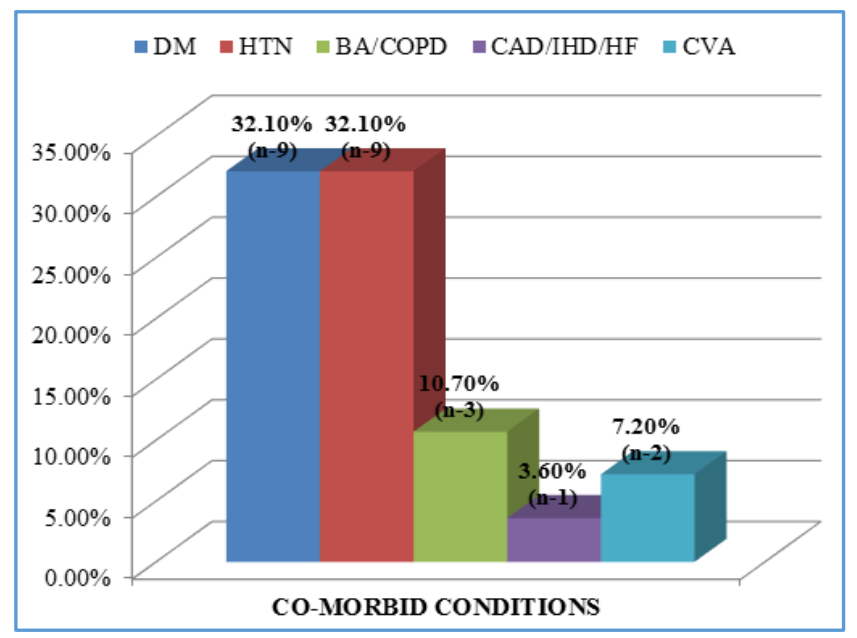

Fig. 1: Comorbid Illnesses of Patients with H1N1 Bronchopneumonia

Fig. 3: APACHE II Scores of Patients with H1N1 Bronchopneumonia

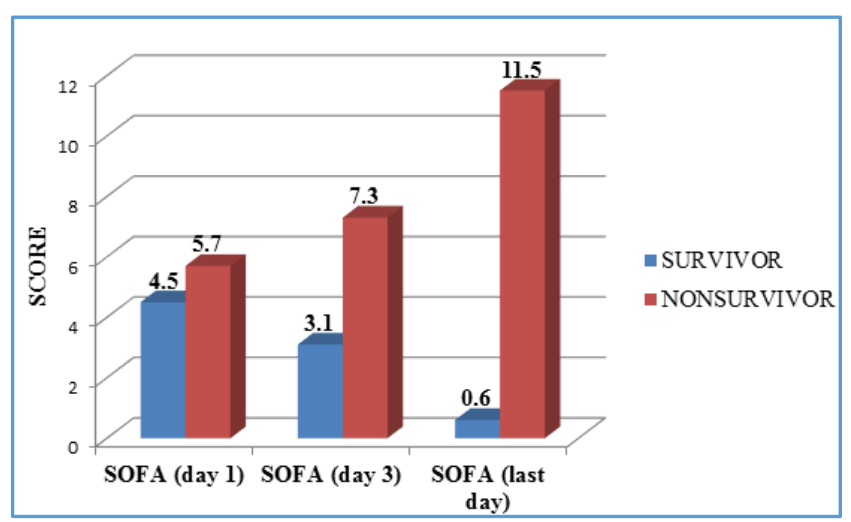

Fig. 4: SOFA Scores of Patients with H1N1 Bronchopneumonia

\section{DISCUSSION}

28 patients were admitted to Intensive care unit during the study period. Our patients were older $[50.6( \pm 19.1)$ years $]$ compared to patients from Canada. ${ }^{4}[32.3( \pm 21.4)$ years] and china 23.4 (mean) years. Majority of patients were females (60.3\%), which was similar to study by Kumar. ${ }^{4}$ et al (67.3\%). On the contrary, Indian study by Chacko. ${ }^{7}$ et al reported lower (46.4\%) incidence of H1N1 bronchopneumonia among females; $25 \%(n-7)$ of our patients were in the peripartum period and their mortality was $100 \%$. Pregnant women were 
more susceptible to infection by H1N1 influenza virus and they are at disproportionately high risk of mortality.9-10 All these patients had severe ARDS; their mean $\mathrm{PO}_{2} / \mathrm{FIO} 2$ ratio (70.15 \pm 15.82 . Five $(5 / 7)$ of our patients were in third trimester and the other two were immediate post-partum.

A variety of cardiac, respiratory, hormonal and immunologic changes that occur during pregnancy may contribute to the increased risk of influenza-related morbidity and mortality among pregnant women. Although it is unknown how long after delivery these changes persist, some of them (i.e. immunologic alterations) might persist longer than others, although some studies of seasonal influenza have not shown an increased period of risk during the postpartum period.11-14

Patients were sick on admission to intensive care unit as indicated by high APACHE II $(17.75 \pm 6.5)$ and SOFA (5.25 \pm 1.8$)$ scores; Cherit. $^{3}$ et al reported a similar high APACHE II $(20.1 \pm 11.9)$ scores from Mexico, whereas Chacko. ${ }^{7}$ et al reported lower APACHE II (13.9 \pm 6.9 scores) among Indian patients. The reason for high APACHE II scores in our patients was high incidence of multiorgan failure in our patients. Respiratory failure was the most common organ failure (96.5\%); this was similar to previous Chacko. ${ }^{7}$ et al study was $83.9 \%$ of their patients had respiratory failure. Followed by lung, renal involvement was seen in $57 \%$ of patients, which was higher than $35.5 \%$ AKI reported by Chacko. ${ }^{7}$ et al.

Mortality rate in our patients was $60.7 \%$, which was higher compared to the Mexican study by Cherit et $\mathrm{al}^{3}$ $(41.4 \%)$ and the Indian data by Chacko et $\mathrm{al}^{7}$ (16.1\%). Mortality rates in $\mathrm{H} 1 \mathrm{~N} 1$ bronchopneumonia is quite varied; it ranges from $7-41.4 \% .15-19$ The higher mortality rate in our study was probably because of the higher severity of illness of our patient population compared to Chacko. ${ }^{7}$ et al (Mean APACHE II $(17.75 \pm 6.5$ vs $13.9 \pm 6.9) ; 85.7 \%$ of our patients had more than one organ dysfunction at the time of admission to ICU. Patients who died had rapidly worsening organ failure as indicated by rapidly rising SOFA scores. The mean day 3 SOFA score in these patients were 7.3 and worst SOFA was 11.5 compared to 5.7 on admission. This indicates that mortality in our group of patients was primarily due to multi-organ failure, unlike the Mexican. ${ }^{3}$ study wherein respiratory failure was the primary cause of mortality.

\section{CONCLUSION}

Critical illness due to H1N1 influenza virus occurred rapidly after hospital admission and was associated with severe hypoxaemia, multisystem organ failure, a requirement for prolonged mechanical ventilation and the frequent use of rescue therapies. Mortality was high among pregnant women.

\section{REFERENCES}

1. World health organisation. Pandemic (H1N1) 2009 update 75. Updated 2009 November 20; cited November 20, 2009. Available from:http://www.who.int/csr/don/2009 22 20a/en/index.html.

2. World health organisation. Influenza a (H1N1): pandemic alert phase 6 declared, of moderate severity. cited November 20, 2009. Available from:http://www.euro.who.int/influenza/AH1N1/200 90611_11.
3. Domvnguez-Cherit G, Lapinsky SE, Macias AE, et al. Critically Ill patients with 2009 influenza a(H1N1) in Mexico. JAMA 2009;302(17):1880-7.

4. Kumar A, Zarychanski R, Pinto R, et al. Critically ill patients with 2009 influenza a(H1N1) infection in Canada. JAMA 2009;302(17):1872-9.

5. Webb SA, Pettila V, Seppelt I, et al. Critical care services and 2009 H1N1 influenza in Australia and New Zealand. N Engl J Med 2009;361(20):1925-34.

6. Goodnight WH, Soper DE. Pneumonia in pregnancy. Crit Care Med 2005;33(10):S390-7.

7. Chacko J, Gagan B, Ashok E, et al. Critically ill patients with 2009 H1N1 infection in an Indian ICU. Indian J of Critical care medicine 2010;14(2):77-82.

8. Puvanalingam A, Rajendiran C, Sivasubramanian K, et al. Case series study of the clinical profile of H1N1 swine flu influenza. JAPI 2011;59:14-6,18.

9. Siston AM, Rasmussen SA, Honein MA, et al. Pandemic 2009 influenza a(H1N1) virus illness among pregnant women in the United States. JAMA 2010;303(15):151725.

10. Cao B, Li X-W, Mao Y, et al. Clinical features of the initial cases of 2009 pandemic influenza a(H1N1) virus infection in China. N Engl J Med 2009;361:2507-17.

11. Janice KLouie, Meileen Acosta, Denise J Jamieson, et al. Severe 2009 H1N1 influenza in pregnant and postpartum women in California. $\mathrm{N}$ Engl $\mathrm{J}$ Med 2010;362:27-35.

12. Neuzil KM, Reed GW, Mitchel EF, et al. Impact of influenza on acute cardiopulmonary hospitalizations in pregnant women. Am J Epidemiol 1998;148(11):1094102.

13. Jamieson DJ, Theiler RN, Rasmussen SA. Emerging infections and pregnancy. Emerg Infect Dis 2006;12(11):1638-43.

14. Echevarria-Zuno S, Mejia-Arangure JM, Mar-Obeso AJ, et al. Infection and death from influenza a H1N1 virus in Mexico: a retrospective analysis. Lancet 2009;374(9707):2072-9.

15. Donaldson LJ, Rutter PD, Ellis BM, et al. Mortality from pandemic a/H1N1 2009 influenza in England: public health surveillance study. BMJ 2009;339:b5213.

16. Miller E, Hoschler K, Hardelid P, et al. Incidence of 2009 pandemic influenza a H1N1 infection in England: a cross-sectional serological study. Lancet 2010;375(9720):1100-8.

17. Louie JK, Acosta M, Winter K, et al. Factors associated with death or hospitalization due to pandemic 2009 influenza a(H1N1) infection in California. JAMA 2009;302(17):1896-902.

18. Jain S, Kamimoto L, Bramley AM, et al. Hospitalized patients with 2009 H1N1 influenza in the United States, April-June 2009. N Engl J Med 2009;361:1935-44.

19. Noah MA, Peek GJ, Finney SJ, et al. Referral to an extracorporeal membrane oxygenation center and mortality among patients with severe 2009 influenza a(H1N1). JAMA 2011;306(15):1659-68. doi:10.1001/jama.2011.1471. 